\title{
Vocational teachers' identity formation through boundary crossing
}

\author{
Andreas Fejes and Susanne Köpsén
}

\section{Linköping University Post Print}

\section{Tweet}

N.B.: When citing this work, cite the original article.

This is an electronic version of an article published in:

Andreas Fejes and Susanne Köpsén, Vocational teachers' identity formation through boundary crossing, 2014, Journal of Education and Work, (27), 3, 265-283.

Journal of Education and Work is available online at informaworldTM:

http://dx.doi.org/10.1080/13639080.2012.742181

Copyright: Taylor \& Francis (Routledge): SSH Titles http://www.routledge.com/

Postprint available at: Linköping University Electronic Press

http://urn.kb.se/resolve?urn=urn:nbn:se:liu:diva-85483 


\title{
Vocational teachers' identity formation through boundary crossing
}

Andreas Fejes and Susanne Köpsén

Linköping University

andreas.fejes@liu.se

\section{Full reference:}

Fejes, A. \& Köpsén, S. (2014) Vocational teachers' identity formation, Journal of Education and Work, 27(3), 265-283.

\begin{abstract}
Vocational teachers' prior occupational experiences are construed as those that will guarantee high-quality teaching in vocational education, although individuals are no longer required to have formal teaching qualifications to be employed as teachers in Sweden. This lack of strict requirements raises the issue of the preparedness of vocational teachers to teach their subject matter. Drawing on a socio-cultural understanding of identity, and based on twenty semi-structured interviews with vocational teachers in different subject areas, this article addresses vocational teachers' identity formation through boundary crossing; these individuals cross boundaries between the community of the prior occupation's practice, the teaching occupation and the community of teacher training. The analysis illustrates how teachers who manage to balance their teacher identities with their occupational identities by maintaining their participation in the different communities seem to be the best prepared to teach their vocational subjects. As many of those we interviewed do not manage to keep such a balance, we argue for the need for in-service training for vocational teachers to help them keep up to date with, participate in and continue to belong to the communities of their former occupations.
\end{abstract}

\section{Introduction}

Vocational education has been emphasised as a solution to the challenges of the future of the European Union and its member countries. By increasing the number of participants in such education, the number of educated workers will increase, as will the prosperity of the EU (European Commission, 2010). Similar narratives can be observed in Sweden, where more and better-prepared vocational workers are suggested as a solution to meet the future demands of the labour market (Ministry of Education, 2009). As an outcome, we have the emergence of a "new vocationalism" (Field, 2005) spreading across Europe, with translations into national policymaking and change. In Sweden, such vocationalism has resulted in an expansion of vocational education, especially at the post-compulsory level (Fejes et al., 2009), and in the establishment of a new teacher training programme for vocational teachers aimed at creating better qualified vocational teachers (Ministry of Education, 2009, 2010). This article contributes to such discussion by focusing on how teachers develop identities as vocational teachers by boundary crossing between their prior occupations, teacher training and their current occupations as teachers.

Within vocational education, the connection between the educational and occupational practices is essential (Ministry of Education, 2009). The connection is made in two main 
ways: the practicums/placements of students in workplaces and the employment of teachers who are experienced in the occupational community about which they teach. In such a way, pupils are exposed to both the logic of production, which dominates workplaces, and the logic of teaching, as is dominant in the educational system (Ellström, 2009). The occupational practice is shaped by one specific socio-culture and the school practice by another, and these practices should interrelate during the educational programme. The differences in socio-cultures are both enabling and constraining for pupil learning in vocational education (Tanggaard, 2007), and the vocational teacher plays a crucial role in connecting these different cultures to enable the pupils to be successful. To be able to do so, the vocational teacher needs to be competent in relation to both socio-cultures. This means having the knowledge and skill to teach in vocational education as well as competence in the modern practice of the specific occupation. In other words, the vocational teacher needs to have both an identity as a teacher and an identity related to the occupation about which he or she teaches. Thus, it is important to further develop knowledge about vocational teachers' identity formation in relation to these two different socio-cultures.

Teaching a vocational subject is different from teaching a theoretical one; the former focuses on knowledge and skill that the teacher has acquired from his or her own experience and participation in the occupational community, whereas the latter is based on knowledge gained mainly at the university level. The extensive research on teacher professionalism (cf. Hargreaves, 1994; Helsby, 1999) provides general conceptualisations of issues of teacher professionalism, whereas the limited, although growing, area of research on vocational teachers' professionalism has started to provide knowledge of the problems and challenges related to working at the intersection of the occupational and educational practices, as well as how this process shapes the identities of vocational teachers (cf. Berner, 1989, 2010; Shain \& Gleeson, 1999; Avis et al., 2002; Robson et al., 2004; Bathmaker \& Avis, 2007; Vähäsantanen \& Eteläpelto, 2009; Vähäsantanen et al., 2009). These studies illustrate how identity is shaped by teachers' involvement in different communities of practices (cf. Wenger, 1998): the practice of the occupation, the practice of teaching, and the practice of teacher training. One could see this phenomenon as a type of multi-contextual learning that takes place through boundary crossing (Milana et al., 2010; Østerlund, 1997; Wenger, 1998), referring to the teachers' participations across contexts, through which they gain access to widening professional and personal positions over time. It is therefore necessary to focus on such movement across boundaries to gain a deeper understanding of how the identities of vocational teachers are shaped. The aim of this article is to analyse the ways the identities of vocational teachers are shaped through their boundary crossings between different practices. More specifically, we will focus on teachers' learning trajectories into becoming and "being", or working as, vocational teachers, drawing on concepts from a socio-cultural tradition to conduct our analysis.

We will first provide a brief background of vocational education in Sweden and the occupation of vocational teacher. This background will be followed by an introduction of the theoretical concepts used in the analysis and an introduction of our empirical material and methodological considerations. Thirdly, we will present our analysis, and finally, we 
will summarise our findings and outline some implications.

\section{Vocational education and vocational teachers}

Vocational education in Sweden is arranged in different ways: vocational education at the upper secondary level (USVE), post-secondary vocational education (often in collaboration with trade and industry), vocational education provided by folk high schools and vocational education at the upper secondary level for adults. This article is based on a study of vocational teachers engaged in USVE for young people aged 16 to 20 years. Generally, USVE is organised into 14 syllabi over three years of study, of which 15 weeks (at a minimum) are in the form of a practicum in a workplace in the vocational community (Ministry of Education, 2009). However, USVE can also be arranged as an apprenticeship, with $2 / 3$ of the time in a workplace and $1 / 3$ at school. As mentioned, the need for competent vocational teachers has been stressed (Ministry of Education, 2009). In line with such reasoning, policy initiatives have resulted in the creation of a new teacher training programme for vocational teachers (Ministry of Education, 2010). The basic idea is that vocational experience is needed to be eligible for the programme. Through the programme, the teachers are supposed to acquire the competencies necessary to teach their vocational subjects. Furthermore, a close connection and collaboration between the educational system (i.e., the vocational teachers) and the labour market is viewed as essential.

However, there are contradictions in contemporary policymaking in regards to vocational teacher training. High quality vocational knowledge and skills are perceived as critical to be a successful vocational teacher, whereas competence in teaching is viewed as a complement. Thus, vocational teachers are encouraged to attend teacher training to complement their vocational knowledge and skills. At the same time, although there is a strong emphasis and new regulations requiring all teachers to have teacher qualifications to become permanently employed as teachers, vocational teachers are exempt from the requirement (Reinfelt et al., 2010). Thus, despite the major policy initiatives in vocational education and the talk of better-qualified vocational teachers, the result is that vocational teachers do not need any formal teaching qualifications.

Despite a previous mandatory teacher qualification, many vocational teachers lacked the formal competence to teach when entering the community of teaching. They were employed despite lacking appropriate degrees, as there is a general shortage of vocational teachers in Sweden. However, many of them, encouraged by their principals, attended a teacher-training programme while working as teachers. Thus, today, many vocational teachers are formally educated.

\section{A socio-cultural approach to identity formation}

This article draws on a socio-cultural approach to identity formation (Lave \& Wenger, 1991; Wenger, 1998). Specifically, we use the concepts of learning trajectories, identity, community of practice and boundary crossing. As individuals take part in different communities of practice, including privately and in education and the workplace, their identities form trajectories, both within and between communities (Tanggaard, 2007). For this study, we see that the trajectory of developing an identity as a vocational teacher may 
be shaped in and move between multiple contexts.

With a socio-cultural approach, learning is viewed as an integral aspect of social activities within a community of practice (Lave \& Wenger, 1991; Wenger, 1998). Learning is an inseparable process of identity formation in which the newcomer gradually develops his or her capability to participate, as well as developing the shared repertoire of the community of practice. Identity formation is about acquiring the knowledge and competencies needed to understand and carry out the common goals of the specific community of practice - knowing how to solve work tasks, what tasks are more important than others, how to communicate with each other, and so on. Furthermore, the participant develops the competence necessary to use the joint repertoire of the community (intellectually and physically), including values, traditions, symbols and language. Identity is about having the competence to participate in a certain social practice, and such competence includes the individual as "a whole". Thus, identity is about belonging; that is, being a member of social practices. The concept of the learning trajectory refers to this gradual development of an identity in practice. The concept directs the focus to the individual's apprehension of learning and his or her involvement in social practice limits, making possible certain trajectories and identities. A trajectory of participation is, thus, connected to socio-material practice rather than simply life stories (Pedersen \& Nielsen, 2009).

The formation of the identity of a vocational teacher occurs through his or her engagement and participation in different communities of practice. Tanggaard (2007) calls participation and the movements between different practices "boundary crossing". This term refers to participation across contexts, through which a person gains access to widening professional and personal positions over time. In our study, this means that the identities of vocational teachers are shaped in different practices, and a crossing between these practices provides opportunities to encounter both the familiar and the strange; in this way, learning occurs.

Participants' developments of joint repertoires and identities within a community of practice represent a continuous process of negotiations of meanings between individuals, concerning both issues of what one is supposed to do and how one will go about doing these things (Wenger, 1998). The construction of an identity is, therefore, the result of individuals' participations in communities of practice, and the social interactions within these practices are crucial for the shaping and re-negotiation of identities. This line of reasoning implies that identity in and belonging to a specific community of practice are constantly negotiated in practice. Thus, an identity is not static but is influenced by the intensity of engagement and participation in a specific community of practice. Moreover, identities are constantly shifting and being shaped in relation to the communities of practice in which we take part. According to this study, this effect means that the influence of an occupational identity on the teacher's identity is individual and may change over time, according to the teacher's movement between and participation in different communities of practice.

In this article, our interest is in analysing how the identities of vocational teachers are 
shaped through their relations with and movements between their occupations as communities of practice, their occupations as teachers (as communities of practice) and their participation in teacher training programmes as communities of practice. This conceptualisation means that the identities of vocational teachers will include, to a larger or smaller extent, belonging to three social practices.

\section{Empirical materials and methods}

The article is based on twenty semi-structured interviews with vocational teachers in different vocational areas who are engaged in teaching in USVE. We aimed for a diverse sample of teachers to gain access to different types of vocational and teaching practices. The teachers have all participated in teacher training, either before becoming a teacher or while working as a teacher. Each interview took 45 to 60 minutes and covered questions regarding the teachers' trajectories into becoming vocational teachers, their experiences in teacher training, their experiences with in-service training opportunities and their relationships with their occupational communities. Each interview was transcribed verbatim.

The result of the study is presented with two "voices" - the emic and the etic perspectives (Lett, 1996); that is, through quotes and field notes, as well as our theoretical interpretations. When the vocational teachers speak about their identities, they use everyday language (e.g., "feeling like" a construction worker or a teacher, which we interpreted as a feeling of belonging). The socio-cultural perspective refers to belonging to a certain social practice, including having an identity and being a member of the social practice. Thus, with our theoretical frame of identity formation as a starting point, we have, through close examination of the transcripts, focused on how the teachers describe their participation and engagement in different communities of practice, as well as why and how they move among these communities. When participating in different communities of practices, one's identity shifts; at the same time, a person might construct one identity in one practice and a different one in another practice. Our analysis will illustrate differences in how vocational teachers construct their identities in relation to belonging to occupational communities, as well as in relation to belonging to teaching communities. However, there is no coherent or clear-cut identity as either a teacher or an occupational worker. Rather, the identities are complex, multilayered and shifting. By identifying the movements and belongings that seem important in constituting a vocational teacher's identity, it is possible to arrive at a starting point, from which we can problematise identity formation among vocational teachers.

\section{Results}

The results section is divided into three parts. First, we discuss movements between the community of teacher training and that of teaching, followed by an analysis of belonging to an occupational community. Thirdly, we focus on movements between the community of teaching and that of the occupation. We end the article by raising some key issues and implications.

Boundary crossing between the community of teacher training and the community of teaching 
All interviewees have formal teacher training degrees, and some have also participated in other courses in higher education. In this section, we illustrate how movement across the community of teaching and teacher training is important in shaping teacher identities. Such movements are not clear-cut, however, and identities are shaped differently.

The movement is clear in relation to one interviewee who graduated as a vocational teacher nine years ago (Helena). Helena notes that she identifies herself as a vocational teacher and describes her trajectory as that of being a competent, proud hairdresser who wished to develop another career. Helena chose the teaching profession based on an interest in pedagogy, which followed her experience as a supervisor for apprentices in her hair salon. Thus, her teacher identity is interdependent with her occupational identity as a hairdresser. Here, there is a change of identity as part of her career path within her occupation (cf. Milana et al., 2010).

A movement between the two identities is also visible in an interview with a teacher in electricity and installation (Karin). Karin recently graduated from the teacher training programme, and she has been a teacher for a short time, with recent experience in the occupational community. Karin says:

I really believe so, and both of us, we are very strong in our teacher identities and also our occupational identities, so if one identity doesn't work we have tools to try things in another way.....

Here, Karin explains that she and her colleague, both being 'younger' among the staff at their school, have strong teacher and occupational identities. However, throughout the interview, the focus is on her identity as teacher, when she states, for instance, that she would rather introduce herself as a teacher than as an electrician when asked about her occupation. Such a move towards a teacher identity, despite her recent occupational experience, seems to be related to her having recently graduated from the teacher training, in combination with her present studies in a master's programme at the university. In other words, her recent and extensive participation in the academic community had an impact on how she construes her identity as a vocational teacher. Such experience provides her with different tools and another language through which she can construe and speak about herself in terms of who she is.

A strong teacher identity is also construed in a situation in which there is movement between the teacher and teacher training communities. A teacher at the Restaurant and Food Programme (Hanna) recently graduated from the teacher training programme, and she continuously participates in courses at an institution of higher education. Hanna strongly emphasises the need for vocational teachers to have a teacher training degree, saying "you can't enter the world of school and not have taken [the teacher training programme]". Hanna relates this need to her older colleagues, who do not have, according to Hanna, the teaching skills necessary to do a good job; she does, on the other hand, acknowledge their occupational skills. Hanna herself, however, does not have significant experience in the occupational community about which she teaches her pupils. Therefore, the tools and language available to her are, to a large extent, those that are 
offered at the university level. Thus, arguing for the need of a degree to teach becomes an important aspect of how she construes herself as a good teacher, a teacher who might even be better prepared than her colleagues; this assertion is a way of gaining legitimacy in the community of teachers.

The picture becomes even more complex when we focus on those teachers who did not have any formal teaching qualifications when starting out as teachers, which is a common case among the interviewees in our study. Rather, it was during their time as teachers that their employers demanded that they attend teacher training, often in order for them to keep their jobs. Thus, they first moved from the occupational community to the community of teaching and then, later on, into the community of teacher training. Despite the seemingly coercive reason behind their entering teacher training, such training seems to have had an impact on shaping the participants' teacher identities. One teacher says:

I can tell you it has taken some time, but now I say that I'm a teacher because I feel like a teacher, but in the occupation [electrician], and yet I still belong to the occupation. (Christian).

Christian further states that teacher training has contributed to making him feel more secure in his role as a teacher. Making the picture even more complex, this person chose to become a teacher partly due to his health, which did not allow him to keep working as an electrician. Being a teacher was one way for him to keep his identity as an electrician:

Partly egotistically, I can still keep my occupation [as an electrician]...and I still get to be part of the occupational community by having contacts with companies where we have placements, but still in another occupation [as a teacher]. So, I really have two occupations contained in one; yes, it is both teaching and electricity, as I have to keep up with the occupation as an electrician, including all the new things that come out and the new standards, changes and new materials, new measuring instruments. New stuff continuously emerges.

This teacher illustrates how his movement between communities of practice shaped his occupational and teacher identities in specific ways. Although he clearly states that he now feels like a teacher, he also retains a strong feeling of belonging to the occupational practice of an electrician; being a teacher allows him, despite his health problems, to still be a member of his occupational community.

In this section, we have observed how participation in a teacher training community develops special knowledge and skills for teaching, something that influences the way the interviewees construe their teacher identities. At the same time, participation in a teacher training community has a significant influence on vocational teachers' belonging to the community of teaching. A vocational teacher should have the general competence to teach, which the interviewees have developed in the practice of teacher training and in the practice of actually teaching. However, the teachers should also have the competences to teach their specific vocational subjects. Having taken part in teacher training communities, the interviewees have developed competences that function as boundary 
objects (Wenger, 1998, 106) between the occupational community and the community of teaching; in other words, competence in connecting knowledge and skills related to the community of occupational practice with the practice of teaching. They have developed vocational teacher identities, meaning that they have the skills to transform their occupational experiences and competences into the ability to teach their specific vocational subjects.

Furthermore, participation in a teacher training community helps construe a teacher's identity as a legitimate member of the teacher community. This participation seems to be particularly important for those vocational teachers with little experience in and weak belonging to their occupational communities (i.e., weak occupational identities). It also seems important for those interviewees who had recently attended programmes for teacher training and crossed the boundary into the community of teaching. They construed themselves as members of the teaching community (i.e., they had developed identities as teachers).

Thus far, we have demonstrated that learning trajectories that move through teacher training play large roles in how the interviewees construe their identities as teachers. In the next section, we will focus on how teacher identities are construed in relation to the occupational community.

\section{Belonging to the occupational community}

The identities related to a specific occupational community played a significant role in how the interviewees construed their vocational teacher identities. Some interviewees talked about strong feelings of pride in their occupational identities, while others spoke about vague occupational communities or having had weak experiences in occupational communities.

We can see that some interviewees expressed great pride in relation to their occupational identities, and this pride characterised the formations of their identities as vocational teachers. The pride was related to the specific occupations (i.e., construction worker, electrician, hairdresser). Speaking about their work as teachers, these interviewees highlighted the importance of the relation to the occupational community, and they still described themselves as, for instance, construction workers and electricians. Most of these interviewees still participate in the communities of their occupations. In other words, they still belong to their occupational communities, and they continue to move between their occupational communities and the teaching community, thus having double memberships.

Pride was an issue in an interview with an electricity and installation teacher (Henry). Henry emphasises that he feels like an electrician: "According to me, I'm still an electrician". Henry even has a business card stating that he is an electrician. He further argues:

I'm still a service person. Before, I serviced my customers who phoned me, and now I serve the pupils who are going to acquire knowledge, that's for sure...I find 
it difficult to call myself a teacher...that's what it says on my business card [electrician]....and then I still have my pride. I'm an electrician and I'm proud of it.

For this teacher, occupational identity is important, and he transfers such identity and some of its characteristics when shaping his teacher identity; in both cases he is "still a service person'.

Pride was also obvious in the case of a construction work teacher who construes himself as a construction worker rather than as a teacher (Oscar): "I still feel like I'm a construction worker when I enter the classroom, yes I do". This teacher perceives his teaching as a practice in which he is a construction worker rather than a teacher. This type of identity is further accentuated in the following quotation:

When I go out and visit the construction sites [where the students do their practicum], I tell them that I work in the Construction and Installation Programme. I want, I don't really want to tell them that I work as a teacher, I don't want to use that, I don't know ...., to me it doesn't sound good. (Oscar)

Here, we can see that his identity as a construction worker seems to be important in relation to the community of construction work. Positioning himself as a construction worker who is working in the Construction and Installation Programme, rather than as a teacher, seems to be a strategy for gaining credibility within the occupational community. The identity as a construction worker, for Oscar, seems to be construed both through teaching and through the relation to the occupational community.

Thus far, we have observed how a strong relationship, or at least proud identification with the occupation, construes a strong occupational identity. In contrast to the above, we can see how those teachers who have weak relations with their occupational communities as an effect of an indistinct and unclearly defined occupation are more likely to hold stronger teacher identities. This was the case for a teacher in the Child Care and Recreation Programme (Madeleine). Madeleine said that this weak occupational identity was a problem not only for her as a teacher but also for her pupils, who had difficulties identifying what occupational community they were being prepared for.

... I have pupils who want to be police officers, nannies... and those who want to be child psychologists... there are such variations. It's a field of general and useful knowledge; how do we communicate? If it doesn't work, why is that? How have we become the persons we are? /.... It's a vocational programme, though there is nothing practical... For example, we don't change diapers, we don't .... the practical thing is to write reports .... (Madeleine)

Furthermore, those who are less skilled and experienced are also more likely to construe stronger teacher identities than occupational ones. This was the case for a teacher in the Restaurant and Food Programme (Albert) who has limited relation to and experience in the occupational field. Rather, Albert entered the teacher training programme to become a teacher. "I want to become more confident in my role as a teacher and learn how to 
evaluate and rate and to design courses in a good way".

In sum, those interviewees who expressed weak or lacking occupational identities construed distinct teacher identities. This phenomenon seems to be reinforced by the fact that none of the interviewees expressed any interest in developing their vocational knowledge and skill. Instead, they expressed interests in developing general knowledge and skill in teaching, perhaps to develop teacher identities.

This section indicates that a learning trajectory that includes strong identification with and sense of belonging to an occupational community may create boundaries in relation to the community of teaching. The vocational teachers describing such a learning trajectory seem to construe themselves as still belonging to their occupational communities and not fully accepting membership in the community of teaching. In the case of the construction work teacher (Oscar), he acts and defines himself more like a supervisor of a building site (see also Berglund, 2009).

Furthermore, this section indicates that vocational teachers describing learning trajectories that include little or no identification with the occupational community construe identities that stress membership in the teacher community.

\section{Boundary crossing between the community of teaching and the occupational community}

We can see how the time elapsed since working in the occupational community and the progress made in the occupational community (e.g., new demands on occupational knowledge and skill) appear to have a significant impact on how vocational teachers construe their identities. Those who have been part of the community of teaching for a long time seem to construe distinct and strong identities as teachers, although there are differences in how they manage to continue belonging to their occupations (i.e., to uphold an occupational identity that includes the contemporary knowledge and skill of the occupation). Three strategies for retaining occupational identity were observed among the vocational teachers: 1) some vocational teachers construed strong teacher identities and struggled to keep up to date with developments in their occupational fields; 2) other vocational teachers more or less gave up on their ambitions to have relationships with their occupational communities; and 3) some vocational teachers still participated in the communities of their occupations.

\section{Struggling teachers}

Among the first category of vocational teachers, it had been many years since the category members had worked in their occupations, and, thus, they needed to find ways to keep up to date with their occupations and the demands for knowledge and skill. They were trying to retain their occupational identities, but there were lacks of structures and routines in the community of school and changes in the occupational fields that made such work difficult. In these cases, the teacher identity became strong, although not coherent or unquestioned.

For example, there have been extensive changes in the occupational community for 
electricians; new types of communities of practice have been generated. Here, we can see that the vocational teachers expressed a loss of occupational knowledge and skills, as well as the ability to keep up-to-date in teaching the vocational subject. Several of them did not stress distinct occupational identities due to the many years they had been working as teachers combined with the major changes that had taken place in their occupational community and the limited opportunities for keeping up-to-date. A teacher in the Electrical and Energy Programme who has worked in school for 25 years (John) said that it had been necessary to learn about new techniques and engineering and that it had, more or less, been up to the vocational teachers to handle these demands for new competences on their own. For example, John said that they did not use computers when he began teaching; "what I know about computers I have learnt on my own. I've been curious, so I have worked many, many hours overtime". Frans, another teacher in the Electrical and Energy Programme, stated that "there is no money for training/.../I try to read journals on my own".

These examples illustrate how the constraints and limits in the community of school do not seem to provide the necessary conditions, such as time, for this vocational teacher to retain his relationship with the occupational field or his knowledge about the contemporary demands for competence. There are no formal possibilities, such as inservice training, in relation to the vocational subject.

Another example is a vocational teacher in the Vehicle and Transport Programme who has a background as a mechanic (Lennart). It has been many years since Lennart participated in the community of vehicle engineering, and he has been working as a teacher since then. In the interview, Lennart clearly stated that he feels like a teacher, although he reportedly tries to keep up with the developments in his occupational field by reading a lot and talking to people in the occupational community. His reading is combined with producing textbooks and other teaching materials in his subject area. This activity seems to be an important aspect of construing his identity as a vocational teacher, as well as of how he manages to retain his occupational identity.

The struggling vocational teachers tried in different ways to move between the community of teaching and their occupational communities, although double membership is not possible, mainly due to constraints in the community of school. There are no supporting systems of routines and customs promoting such activities. These teachers are aware of the wide changes in their occupational fields and that they need to have relations to their occupational communities to retain their occupational knowledge and skills. The struggling teachers have developed strategies for overcoming the obstacles to boundary crossing, although these obstacles might be, as one of them said, too overwhelming in combination with full-time teaching. This situation will be shown in the following section.

Teachers who have stopped struggling

A structurally closed practice of education and changes in occupation communities have substantial impacts on how some teachers construe themselves as vocational teachers. There are teachers who have strong identities as teachers and who have more or less 
given up their ambitions to keep in contact with their occupational communities. Several years have passed since they actively participated in their occupational communities. They noted that they have lost a lot of occupational knowledge and skills and that they no longer have any apparent relations to their occupational communities.

John, a teacher in the Electrician and Energy Programme who was struggling with working overtime, said:

If you look at the new upper secondary school, there are a lot of things you need to learn...this part [electrical engineering] is so expansive, it's terribly expansive ... because there's so much more than teaching that needs to be done today. You can't take in everything that happens, it's not possible.

He explained that it is not possible anymore, as there is not time for him to keep up with the changes within his occupational area. Frans, another teacher in the same programme, told us that he does not have any relation to his occupational community. He explained why and pointed to the risk of vocational teachers' occupational knowledge not being upto-date:

It's incredibly rapid development, you have to constantly learn. /.../ There is a demand for a new kind of knowledge that I couldn't imagine ten or fifteen years ago /... / We try to visit workplaces when it's the period of placement, but it has been too difficult during recent years. Sometimes we have students left here in school, and we can't leave them alone. We have no substitutes, they don't exist anymore/ ... / Thus, there is a risk with vocational teachers .... you stagnate and stick to the old stuff....

Another example concerns a teacher in the Vehicle and Transport Programme (Kenneth), who told us that he has not worked in his occupational field for over 30 years. Kenneth argued that "actually, I feel like a teacher, that's how it has become". However, these teachers are aware of the process of change in the communities of their occupations, and they try, to some extent, to keep up by reading professional journals, although they realise that this is not enough. They are no longer members of their occupational communities, and so we can argue they have weak occupational identities.

These vocational teachers are also the most likely to teach newcomers in the vocational programme, rather than teaching those in the last year of specialisation. These vocational teachers no longer move among the different communities of occupation, teaching or teacher training. They participate full-time in the community of teaching and construe dominating teacher identities.

Teachers who move between the occupational and teacher training communities

The last group of teachers with strong vocational teacher identities are those who still have close relationships with their occupational fields, thus balancing their teacher identities with their occupational identities. These teachers have managed to handle the challenge of time and/or occupational change by moving between the different 
communities of practice. They have been participating in the occupational community, for instance by doing part-time work in their spare time. Erik talked about driving lorries, saying "I have a wide network, as I'm still in the business, even today on holidays, and so, I take runs". Henry installs electrical wiring: "I'm an electrician, I'm so stupid, so I still think it's fun to work so I still do some". They have also been actively engaged in their students' practicums, as Lennart said: "now I visit the workplaces and watch the students working with the customers' cars and talk to the supervisors". The vocational teachers expressing such trajectories construe vocational teacher identities that stress neither the occupational identity nor the teacher identity. The identities being presented are more of a balanced type, including belongings to the two different communities.

What this section indicates is that there are socio-cultural structures and a lack of a system for in-service training, making it hard for vocational teachers to retain their occupational knowledge and skills, even when there is ambition to do so. Some of these teachers have strategies, such as reading books and producing teaching materials, but do not have the working conditions needed to move across boundaries to the contemporary occupational field. However, there are others who actually still participate in their occupational communities, either by working part time or by being engaged in the practicums of their pupils. Furthermore, there are vocational teachers who have given up the ambition to challenge the structures and to cross boundaries. These results indicate the importance of crossing boundaries to shape a vocational teacher's identity as one who is prepared to teach occupational knowledge and skills that are relevant today. At the same time, it is important to change the practice of school, in terms of establishing resources and routines for in-service training related to occupational identity.

\section{Discussion}

In this article, we have focused on how vocational teachers shape their identities through boundary crossing across three different communities of practice: the community of teaching, the prior occupational community and the community of teacher training. The analysis illustrates how participation in and movement across communities are important for shaping vocational teachers' identities and, in turn, has implications for how wellprepared teachers are in their work as teachers of their vocational subjects. This process can be seen as multi-contextual learning through boundary crossing (cf. Østerlund, 1997; Wenger, 1998).

Our analysis illustrates how participation in the community of teacher training has a significant influence on vocational teachers' belonging to the community of teaching. On the one hand, through such participation they learn how to transform occupational knowledge and skills into the practice of teaching. On the other hand, participation in teacher training helps legitimise vocational teachers as members of the teaching community. We further observe how identification with the occupational community might create boundaries in relation to the community of teaching. Some vocational teachers construe strong occupational identities and do not primarily identify themselves as members of the community of teaching, whereas others have weak relations to the occupational community, stressing, instead, belonging to the community of teaching. We have illustrated how movements between the community of teaching and the 
occupational community are complex and how teachers with strong vocational teacher identities, to varying extents, are successful in combining occupational identities with teacher identities. There are those teachers who struggle to keep up with occupational demands and skills, as many years have passed since they practised their occupations. Due to constraints within the community of teaching (time, resources, etc.), they are not able to maintain their belongings in both communities. Furthermore, there are those teachers who have resigned and construe strong vocational teacher identities. They have not been part of their occupational communities for many years, and they have stopped moving between the two. Finally, there is a group of teachers that continues to move between the two communities by doing part-time work in the occupational community or by being responsible for trainee placements, thus often visiting work sites in their roles as teachers. These teachers are also those who seem to best keep their occupational knowledge and skills up-to-date.

Belonging to both the teacher training community and the occupational community seems to give teachers credibility and legitimacy as teachers. This is interesting in two ways. Firstly, it to some extent contradicts the results found by Robson et al. (2004) that indicate that experience from the prior occupation is what gives these teachers their credibility. Secondly, our results contradict the policy discourse where the occupational experience is positioned as the most important qualification for vocational teachers. Teacher training is encouraged, but not mandatory to be eligible to be employed as a vocational teacher. To understand the relations between occupational experience and formal teaching qualification, we need to turn our attention to contemporary policy debates about the "new vocationalism" (cf. Field, 2005) and the professionalisation debate about the teaching profession in Sweden (Ministry of Education, 2009, 2010).

On the one hand, in policy, it is perceived as essential that more people enter vocational education to meet the demand of the labour market. To meet the labour market's demand for well-trained vocational students leaving school, it is also stressed that vocational teachers should be qualified in the vocational subject they teach. On the other hand, better results in Swedish schools are perceived as achievable by improving the teacher training programme; that is, by only employing teachers who have formal teaching qualifications and by introducing a teaching license. However, as there is a lack of vocational teachers in Sweden, it would not be possible to employ a sufficient number of them if formal teaching qualifications and teaching licenses were mandatory. As a result, the demand for vocational teacher qualifications is lower than that for other types of teachers. Therefore, to raise the competencies and qualifications among vocational teachers, in-service training becomes important.

However, as our results show, the community of school practice does not include a system for vocational teachers to retain their occupational knowledge and skills; the school is constructed as a structurally closed practice. Such situations might invoke a sense of resignation among some teachers who do not feel motivated to keep up-to-date with their occupations, as it takes too much effort on their part. Moreover, in-service training for vocational teachers seems to only include general teacher knowledge and skills and does not relate to vocational teachers' specific needs. In particular, in-service 
training does not include the need to develop competence in teaching vocational subjects. The demands for renewal and higher qualities of vocational education and training indicated in Swedish policy texts do not in any way include the vocational teachers' competence-related conditions for the development of such vocational teaching and training. The policy text points to the importance of young people having the knowledge and skills that meet the occupational demands and to the need for vocational teachers to have the relevant occupational knowledge and skills. Despite these expectations, policy texts do not make any demands for school management guaranteeing vocational teacher competence or supporting vocational teachers' development of relevant up-to-date occupational knowledge and skills.

As mentioned, there are demands for formal qualifications and legitimacy for Swedish teachers, and special arrangements are made for them to meet these demands if needed. However, there are no such demands or arrangements in the cases of vocational teachers. Instead, the importance of vocational teachers' occupational knowledge and skills is highlighted, although there is neither a policy nor financial support for vocational teachers to satisfy this requirement for up-to-date occupational knowledge and skills. Somewhat drastically, it could be said that vocational teachers' current occupational knowledge and skills have become their individual responsibilities, which neither politicians nor school management support or encourage to prepare the teachers for their current teaching practice. These deficient conditions for in-service training for vocational teachers can, in relation to the results in this article, be viewed as obstacles to realising the expected renewal and improvement of Swedish vocational education and training.

\section{Acknowledgements}

The interviews were conducted by Köpsén. Both authors have contributed equally to the analysis and writing of this article.

\section{References}

Avis, J., Bathmaker, A-M. And J. Parsons. 2002. Communities of practice and the construction of learners in post-compulsory education and training. Journal of Vocational Education and Training 54, no. 1: 27-50.

Bathmaker, A-M.. and J Avis. 2007. 'How can I cope with that?' The challenges of 'schooling' cultures in further education for trainee FE lecturers. British Educational Research Journal 33, no. 4: 509-532.

Berner, B. 2010. Crossing boundaries and maintaining difference between school and industry: forms of boundary-work in Swedish vocational education. Journal of Education and work 23, no. 1: 27-42.

Berner, B. 1989. Kunskapens vägar: Teknik och lärande i skola och arbetsliv. Lund. Arkiv förlag. 
Berglund, I. 2009. Byggarbetsplatsen som skola - eller skolan som byggarbetsplats? En studie av byggarbetares yrkesutbildning. Stockholm University: Institutionen för didaktik och pedagogiskt arbete.

European Commission. 2010. Strategic Framework for Education and Training. European Commission. http://ec.europa.eu/education/lifelong-learning-policy/doc28_en.htm. $6^{\text {th }}$ November 2010.

Ellström, P-E. 2009. Lärande i arbetsliv och yrkesutbildning. In Didaktik för yrkeslärare, ed. T. Hansson, 15-38.Lund: Studentlitteratur.

Fejes, A., Larsson., Paldanius, S. and S. Roselius. 2009. Livslångt lärande i nöd och lust. In Lärande på vuxnas vis: Vetenskap och beprövad erfarenhet, eds. M. Abrandt Dahlgren \& I. Carlsson, 19-42. Lund: Studentlitteratur.

Field, J. 2006. Lifelong learning and the new educational order. Stoke on Trent: Trentham Books.

Hargreaves, A. 1994. Changing teachers, changing times: teachers' work and culture in postmodern age. London: Cassell.

Helsby, G. 1999. Changing teachers’ work. Buckingham: Open University press.

Lave, J., and E. Wenger. 1991. Situated learning: Legitimate peripheral participation. Cambridge: Cambridge University Press.

Lett, J. (1996) Emic/Etic Distinctions. In Encyclopedia of Cultural Anthropology. London: Macmillan.

Milana, M., Köpsen, S. and P. Andersson, eds. 2010. BAEA: Becoming Adult educators in the European Area: synthesis research report. Copenhagen: Danish School of Education, Aarhus University.

Ministry of Education. 2009. Prop 2008/09:199 Högre krav och kvalitet $i$ den nya gymnasieskolan. Stockholm: Ministry of Education.

Ministry of Education. 2010. Prop 2009/10:89 Bäst i klassen - en ny lärarutbildning. Stockholm: Ministry of Education.

Pedersen, M. and K. Nielsen. 2009. Laering, konflikter of arbejdsdelning - en udvidelse af den socialt situerede laeringsforståelse. Psyke \& Logos 30: 652-671.

Reinfeldt, F., Olofsson, M., Björklund, J., and G. Hägglund. 2010. Vi inför yrkeslegitimation för alla Sveriges lärare 2012. Dagens Nyheter, 12 april. 
Robson, J., Bailey, B., and S. Larkin. 2004. Adding Value: Investigating the discourse of professionalism adopted by vocational teachers in further education colleges. Journal of Education and Work 17, no. 2: 183-195.

Shain, F., and D. Gleeson. 1999. Under new management: changing conceptions of teacher professionalism and policy in the further education sector. Journal of Education Policy 14, no. 4: 445-462.

Tanggaard, L. 2007. Learning at trade vocational school and learning at work. Boundary crossing in apprentices' everyday life. Journal of Education and Work 20, no. 5: 453466.

Vähäsantanen, K., Saarinen, J., and A. Eteläpelto. 2009. Between school and working life: Vocational teachers' agency in boundary-crossing settings. International Journal of Educational Research 48: 395-404.

Vähäsantanen, K, and A. Eteläpelto. 2009. Vocational teachers in the face of a major educational reform: individual ways of negotiating professional identities. Journal of Education and Work 22, no. 1: 15-33.

Wenger, E. 1998. Communities of practice: learning, meaning and identity. Cambridge: Cambridge University Press.

Østerlund, C. 1997. Sales apprenticies on the move. A multi-contextual perspective on situated learning. Nordisk pedagogik 17, no. 3: 169-177. 